\title{
Challenges of Integrated Vehicle Chassis Control: Some Findings of the European Project EVE
}

\author{
Valentin Ivanov ${ }^{* a)}$ \\ Dzmitry Savitski* \\ Klaus Augsburg* \\ Schalk Els** \\ Cor-Jacques Kat ${ }^{* *}$ \\ Theunis Botha** \\ Miguel Dhaens ${ }^{* * *}$ \\ Corina Sandu ${ }^{* * * *}$ \\ Rui He ${ }^{* * * *}$ \\ Sterling McBride ${ }^{* * * *}$ \\ Angel Gabriel Alatorre Vazquez ${ }^{* 5}$ \\ Alessandro Corrêa Victorino ${ }^{* 6}$ \\ Non-member \\ Non-member \\ Non-member \\ Non-member \\ Non-member \\ Non-member \\ Non-member \\ Non-member \\ Non-member \\ Non-member \\ Non-member \\ Non-member
}

(Manuscript received May 7, 2018, revised July 8, 2018)

The development of high-performance mechatronic systems as well as the strong demand for environmentacceptable and safe intelligent technologies have had a profound impact on vehicle engineering. This impact has resulted in both an increasing degree of automation of vehicular systems and the emergence of new concepts like integrated chassis control. To contribute to this topic, a consortium of several industrial and academic partners from EU, South Africa, and USA has performed consolidated research and innovation actions for the development of new integrated chassis control technologies within the framework of the European project EVE. This paper presents the main EVE outcomes related to the integration of active brake, suspension, and tyre pressure control. Attention is also given to the problems of vehicle and tyre modelling, state estimation, robust chassis control, and experimental validation tools.

Keywords: integrated chassis control, vehicle dynamics, automotive control systems, X-in-the-loop

\section{Introduction}

Progress in automotive engineering technologies is mainly being determined nowadays by two domains-electric

a) Correspondence to: Valentin Ivanov. E-mail: valentin.ivanov @ tu-ilmenau.de

* Automotive Engineering Group, TU Ilmenau, Ehrenbergstr 15, 98693 Ilmenau, Germany

** Vehicle Dynamics Group, Department of Mechanical and Aeronautical Engineering, University of Pretoria Private Bag X20, Hatfield, 0028, South Africa

*** Tenneco Automotive Europe, IZ A Schurhovenveld 1037 3800 St Truiden, Belgium

**** Virginia Polytechnic Institute and State University 460 Old Turner Street, Blacksburg, VA 24061-0710, U.S.A.

${ }^{* 5}$ Heuristique et Diagnostic des Systèmes Complexes (Heudiasyc)-UMR 7253, Université de Technologie de Compiègne

57, Avenue de Landshut, 60200 Compiègne, France

${ }^{* 6}$ Escola de Engenharia, Universidade Federal de Minas Gerais Av Antonio Carlos 6627, Belo Horizonte, Minas Gerais, Brazil vehicles and automated driving. These domains put the substantial research and innovation focus on such topics as environment-friendly powertrains, sensor fusion, vehicle-to$\mathrm{X}$ connectivity, and Artificial Intelligence (AI)-based vehicle control. However, despite promising technological advances in these topics, their potential can be explored only with high-performance automotive chassis systems capable to realize efficient motion dynamics within the framework of electric/automated vehicles. Analysis of state-of-the-art in chassis design shows that a clear-cut trend towards integrated vehicle motion control can be observed now ${ }^{(1)}$. Although this idea for a combined operation of several chassis systems to improve simultaneously various vehicle performance criteria has arisen few decades ago ${ }^{(2)(3)}$, only recent progress in highly dynamic mechatronic actuators made possible concepts of the robust and efficient integrated chassis control (ICC). However, at the same time, it is possible to identify several methodological gaps to be solved for a systematic, holistic approach to designing the integrated chassis control: 
- Consistency of models-More emphasis should be placed to real-time high-fidelity models of the vehicle and its subsystems with the support of their seamless transfer between applications for (i) software simulators, (ii) hardware-in-the-loop (HIL) test setups, and (iii) onboard controllers; one of the main vehicle components with significant challenges here is the tyre, as typically high-fidelity tire models are not suitable for real-time vehicle simulations or HIL;

- Robust control strategies-On the development design stage, a many-sided robustness analysis has to be carried out by the selection of control strategies for both vehicle sub-systems and ICC under consideration of critical operational situations (e.g. inhomogeneous tyre-surface contact); furthermore, this also brings up the need to develop a more adequate parameter estimation technique to be used in conjunction with the ICC;

- Shared testing procedures-An established validation process by designing the control systems usually includes sequential procedures, from the Model-in-theloop (MIL) through the HIL to the experiments on fullscale test rigs and objects. However, the complexity of ICC with the simultaneous demand on an optimized development schedule requires another level of testing paradigms allowing shared real-time experiments involving testing setups from different vehicle engineering domains and situated in various geographical locations; some of the most challenging aspects related to this topic are the compatibility of software and communication protocols among various locations, and the data processing power available at each location.

At a higher level, it can be summarized that a dedicated study on the integrated chassis control requires multidisciplinary research activities with the involvement of various competences. These factors motivated the research project EVE "Innovative Engineering of Ground Vehicles with Integrated Active Chassis Systems" that will be further introduced. This project is realized by the consortium of several industrial and academic partners from EU, South Africa and USA with the following objectives:

- Development of reference tyre models for on-road and off-road conditions to be used in the ICC design;

- Experimental studies to assess the performance of tyres in challenging on-road (i.e., on ice) and off-road (e.g., on soft soil) conditions, to be used for tyre modeling purposes;

- Advancement of integrated chassis control methods with active compensation of external and internal disturbances;

- Development of advanced models of ground vehicles and automotive subsystems for real-time control applications;

- Designing of ICC with simultaneous improvements in driving safety and comfort and realized with brake-bywire, semi-active suspension and dynamic tyre pressure control;

- Development and comparative benchmarking of realtime ground vehicle parameter estimation techniques;

- Development of distributed testing technology allowing cooperative experiments on stationary and mobile hardware-in-the-loop (HIL) test rigs at different hosts.

Next sections will give an overview of the proposed ICC architecture, description of tyre and vehicle modelling activities, control system design as well as validation approach.

\section{Design Aspects of Integrated Chassis Control}

2.1 System Architecture The vehicle demonstrator used in the project works is based on a Sport Utility Vehicle (SUV) having off-road capability. For this demonstrator, the integrated chassis control proposed in the EVE project is addressing a particular design case, which should reflect the following requirements: (i) the system provides coupling of longitudinal and vertical motion dynamics control; (ii) both on-road and off-road driving capability of the vehicle is considered; (iii) participating chassis sub-systems can be operated in stand-alone and integrated modes; (iv) the integration of sub-systems should demonstrate simultaneous improvement of driving safety and comfort. Considering these requirements, the ICC architecture in accordance with Fig. 1 has been proposed.

The ICC architecture is represented with three chassis subsystems. The longitudinal vehicle motion control is realized for a braking mode with the decoupled electro-hydraulic brakes. The multi-level semi-active suspension is responsible for the vertical vehicle motion control. Both mentioned systems are being permanently integrated by the supervisory controller aimed at the optimal vehicle dynamics control in terms of the driving safety and comfort. The third chassis subsystem - the highly dynamic tyre pressure control—is being activated depending on the maneuver conditions to support the braking/suspension control.

2.2 Design Components The development of discussed ICC configuration requires a sophisticated design process consisting of many components as shown on Fig. 2. This process can be represented for convenience with five task groups. Tyre $\mathcal{E}$ Vehicle Modelling tasks cover development

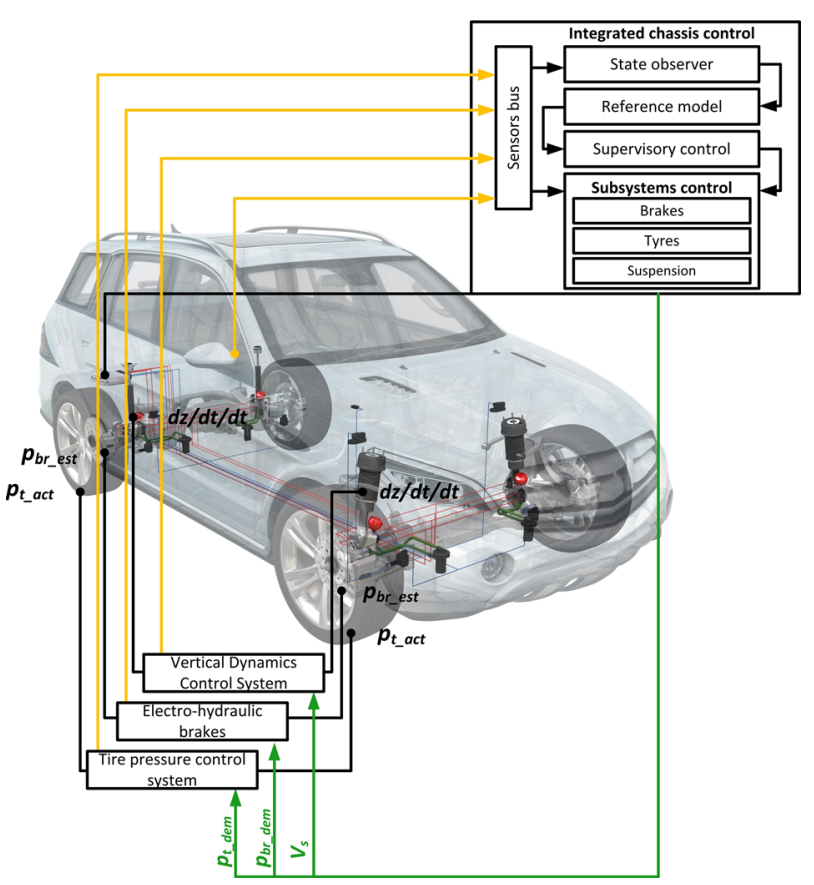

Fig. 1. ICC system architecture (reproduced from (4)) 


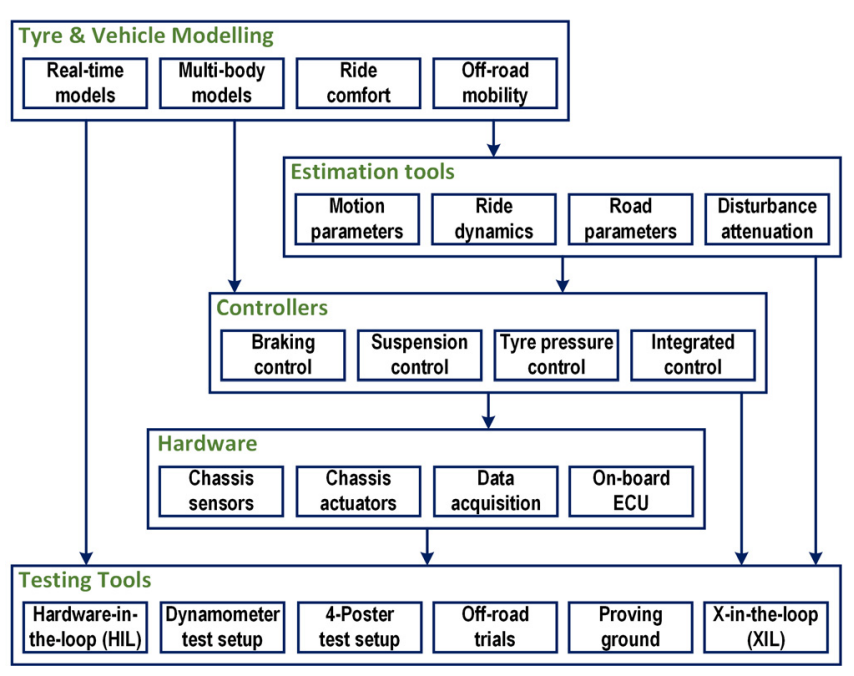

Fig. 2. ICC design components

of

- Real-time models for the subsequent utilization in the sub-system controllers;

- Multi-body models allowing detailed evaluation of the vehicle motion dynamics, e.g. during MIL/HIL studies;

- Specific tyre and vehicle models for the assessment of the ride comfort;

- Specific models describing the vehicle motion in offroad conditions, such as driving over rough or deformable surfaces.

The tasks related to estimation tools include the formulation and development of estimators and observers for ICCrelevant vehicle motion parameters as the velocity, the tyre forces et al. and the road parameters as the friction and the profile. An additional objective is the realization of methods for attenuation of disturbances during ICC system operation caused by such factors as the brake fading, hysteresis in chassis elements, and road unevenness. Furthermore, the design concept requires the development of controllers for braking, suspension and tyre pressure control sub-systems, supplemented with a supervisory integrated controller.

Hardware-related tasks are dedicated to the development and utilization of

- Chassis sensors, e.g. intelligent load-sensing bearings for measurement of wheel forces and torques;

- Chassis actuators as decoupled electro-hydraulic brakes, multi-level semi-active suspension, and tyre pressure valves;

- Data acquisition systems and on-board electronic control units (ECU) for the chassis sub-systems and the integrated controller.

The final group of tasks deals with the testing tools used for the validation and verification of models, controllers, estimators, and the overall system functionality. Here a wide spectrum of approaches is implemented, including:

- HIL setups for studies on actuator dynamics;

- Dynamometers for studies on the chassis loading modes;

- 4-poster setup allowing investigations on the ride comfort;

- Proving ground and controlled conditions laboratory setup for off-road trials needed for the parameterization of tyre and vehicle models and for performance analysis studies;

- X-in-the-loop methodology for the research on complex inter-domain phenomena, which are characteristic for the ICC operation.

It can be concluded that the realization of all mentioned design components has a strong demand on interdisciplinary competences. Therefore, the full development process can be realized only through collaborative design that is explained in next section.

\section{EVE Competence Mapping}

To cover the whole ICC design process, the EVE project has proposed a consortium with a strong interdisciplinary, intersectoral and international balance. The collaborative works united organizations from seven European countries (Germany, Belgium, The Netherlands, Spain, France, UK, and Sweden), South Africa and the USA:

- Industrial sector-Tenneco Automotive, SKF, dSPACE $\mathrm{GmbH}$, Armaments Corporation of South Africa Gerotek Test Facilities, ESTEQ Engineering (Pty) Ltd;

- Academic sector-TU Ilmenau (TUIL), Instituto Tecnológico de Aragón (ITA), Delft University of Technology (TUD), Chalmers University of Technology, Heudiasyc laboratory at University of Technology of Compiègne (UTC), University of Surrey, University of Pretoria (UP), Virginia Tech (VT).

The interaction of the partners and mapping of their competences can be introduced as follows.

1) TUIL and UP cooperated in the development of vehicle models for the controllers of ICC sub-systems. Development of tyre models for on-road and off-road conditions is subjected to collaborative research between VT and UP. Software realization of the models is done using the ASM tools of DSPACE and multi-body modelling tools of ESTEQ, with implementation support from VT.

2) Parameterization and validation of developed tyre and vehicle models included experimental works on the rolling dynamometer of TUIL, terramechanic test bed of VT for ice and soft soil, and proving ground tracks of GEROTEK.

3) The controllers of ICC sub-systems required interaction of TUIL and UP (brake and tyre pressure control systems) and ITA and UP (active suspension) with subsequent inclusion of TUD for the development of global ICC controller. A set of different wheel slip controllers has been investigated and tested in cooperation between SURREY and TUIL for benchmarking and advanced ICC solutions for vehicles with alternative powertrains.

4) New analytical technique for vehicle state and parameter estimation is proposed based on results of cooperation between UTC, ITA, TUIL and VT. The corresponding estimators were integrated into the ICC and validated by real-time tests.

5) The testing of the hardware components of the ICC subsystems, including industrial solutions of TENNECO, has been done on the test rigs of TUIL with the use of DSPACE HIL technologies. This interaction was supplemented with experiments on real vehicles was done by UP, GEROTEK and TUIL.

6) TUD, CHALMERS and SKF performed cooperative 
research for advanced design of load-sensing bearings for multi-purpose vehicle mobility and for integration of new bearing-based wheel force measurement elements into the ICC sub-systems.

7) Collaboration of TUIL, TUD, UP and VT was organized for the realization of distributed real-time experiments on different physical hosts using dSPACE hardware.

Within the framework of the presented paper, several design aspects discovered during the EVE collaboration will be overviewed in next sections.

\section{Design Case: Tyre-Low Friction Surface Characterization}

A rarely investigated area in ICC research relates to the support of the driving stability in severe road conditions. In particular, ice can be recognized as a case where existing vehicle dynamics control system are approaching a limit in achievable improvement by conventional control methods, unless new disruptive control technologies are considered. A frequent problem by developing any driving safety system for ice conditions is to have an adequate specification of the friction $\mu-\operatorname{slip} \lambda$ characteristic. As compared with other surfaces, the $\mu$ - $\lambda$-curve for ice has (i) no distinct extremum that complicates the definition of the optimal operational area of the tyre and (ii) very low values of the reference (optimal) slip that puts increased requirements to the precision by estimating the vehicle velocity and slip. Particularly in the case of the ICC, a wrong definition of the optimal slip area not only deteriorates the driving safety but also increases the wheel slip losses. There are only few proving grounds

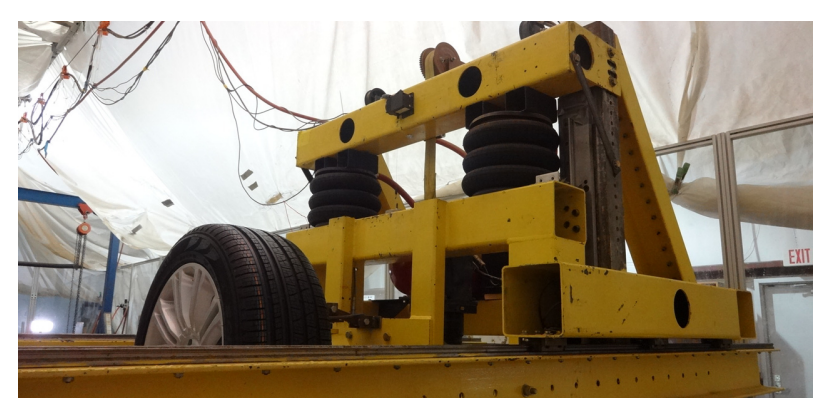

Fig. 3. Tyre testing on ice in the Terramechanic test rig at Virginia Tech

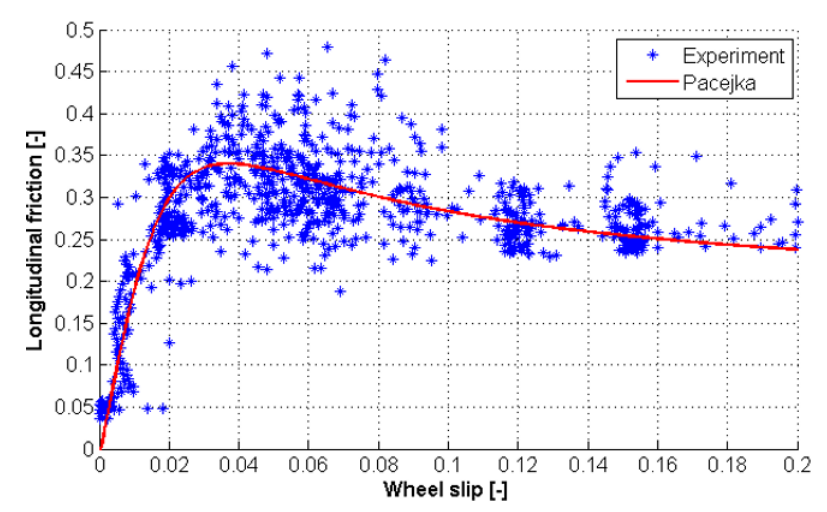

Fig. 4. Example of experimental tyre-ice model parametrization for Pacejka model (5) in the world, which have test road segments with ice and snow surfaces. Therefore, the parametrization of tyre models for such conditions can be very challenging. In the case of the EVE project, a unique terramechanic test rig ${ }^{(6)}$ of the Terramechanics, Multibody, and Vehicle Systems (TMVS) at Virginia Polytechnic Institute and State University has been used, as illustrated in Fig. 3, which was designed for tyre testing on specially prepared real icy surfaces.

The ice temperature can be accurately controlled during the testing; the tire is cooled to the ice temperature prior to the testing. The normal load and the slip ratio in the contact patch are accurately controlled during the test. Figure 4 shows an example of the raw test data collected on the Terramechanics Rig and the processed test results. The processing procedure included complex filtering to achieve exact parameterization of the tyre model even in the area of very low slip (below 0.05). During the tests, the vertical load has been varied to create the database required for the extremum seeking algorithm to finding optimal slip area in relation to $\mu-\lambda$ curves. With the performed tests, the functionality of the traditional tyre models as Pacejka or Dugoff models has been considerably extended. Specifically, the obtained model versions allow to investigate the performance of the integrated chassis controller on low-friction surfaces like ice.

\section{Design Case: Effect of Age and Wear on Tyres}

Vehicle systems are designed with specific tyres in mind and the systems are designed to operate optimally with those tyres. Apart from terrain conditions which may affect the tyre longitudinal force versus slip characteristics, the effect that tyre wear and age has on the tyre longitudinal force and tyre stiffness has rarely been investigated. A study on the effect of wear and age on tyre characteristics was conducted to determine whether the effect is significant and needs to be taken into account in the ICC.

The effect of age on the tyre stiffness was determined by artificially aging the tyre in an oven while inflated with oxygen rich air. This procedure ensured the tyre would have approximately equivalent rubber properties to that of a 4-year-old tyre used in the field in Phoenix, Arizona in the USA according to Baldwin ${ }^{(7)}$. The effect of age on the longitudinal force is shown in Fig. 5. It was found that a maximum of $4.16 \%$ change in stiffness is observed as a result of the aging process.

The effect of wear on the tyre's longitudinal force as a function of slip was determined by wearing a tyre on a tyre test trailer conducting lateral and longitudinal force tests of the tyre. The tyre was run until almost all tread had been worn away. The longitudinal characteristics for the tyre were determined for the new and worn tyre and a Pacejka tyre model fit was conducted. The results show that a $10 \%$ reduction in longitudinal force is observed but that the maximum force is still produced in the same slip range, as shown in Fig. 6. This would result in the maximum affect that the ICC can have, by using the longitudinal force to control the vehicle motion to reduce the tyre wears. However, the aging and wear should not have an effect on the slip-based controller since the maximum force is still achieved in the same slip ranges. 


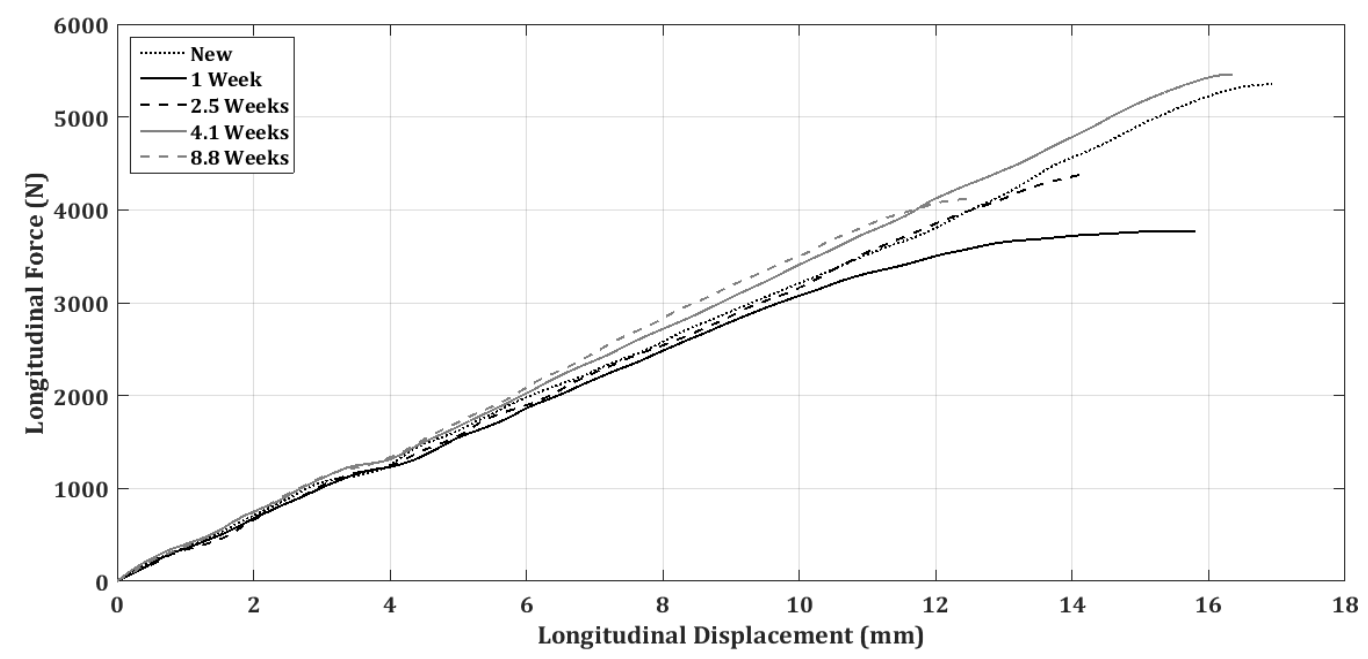

Fig. 5. Effect of tyre age on the tyre longitudinal tyre stiffness

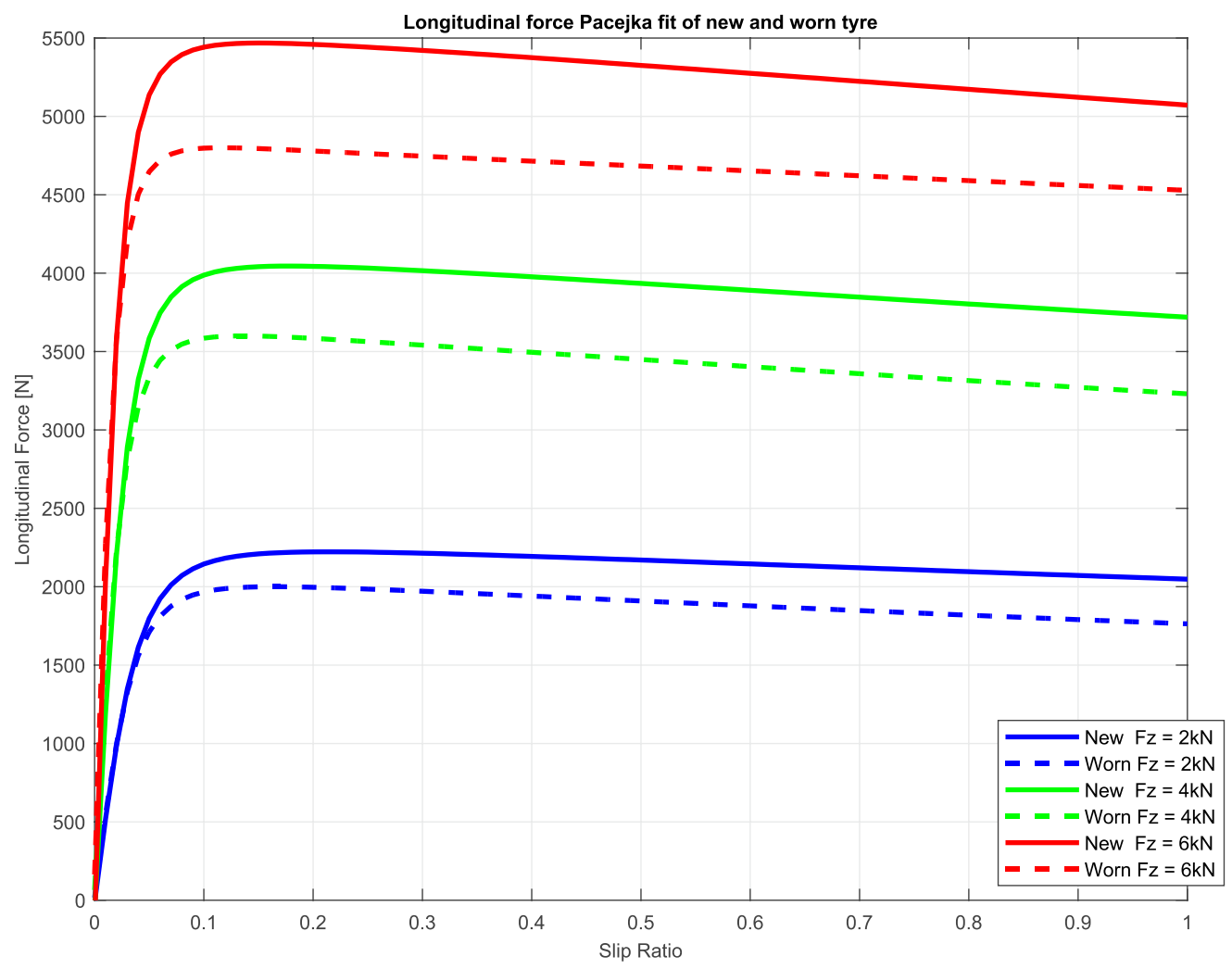

Fig. 6. Effect of tyre wear on the tyre longitudinal force versus slip characteristics

\section{Design Case: Parameter Estimation of Sus- pension Forces and Vehicle Inertial Parame- ters}

The ICC relies on prior knowledge of vehicle parameters to operate in an optimal manner. Since the vehicle parameters may change due to loading conditions the estimation of inertial properties of the vehicle such as mass, location of centre of gravity, roll and pitch centre height becomes important. Other parameters of interest include road grade and elevation as well as road profile. The real time estimation of these parameters will allow for more optimal control of the vehicle. The inertial parameters can be estimated using force measurement at the wheels or suspensions struts.
This however requires the permanent mounting of expensive equipment. While certain technologies are addressing the force estimation such as load sensing bearings ${ }^{(8)}$, the inertial parameters can also be estimated by means of low cost sensors such as accelerometers, gyroscopes and suspension displacement sensors. The strut displacement and velocity are initially estimated using a linear Kalman filter ${ }^{(9)}$. From the strut displacement and velocity, as well as from the suspension model, the strut force can be determined. The estimated suspension forces are then used to estimate the inertial properties of the vehicle using an Unscented Kalman Filter ${ }^{(10)}$. Figure 7 shows the estimated suspension forces compared to the measured forces driving over a Belgian paving surface. Figure 8 shows some of the inertial parameters which are 

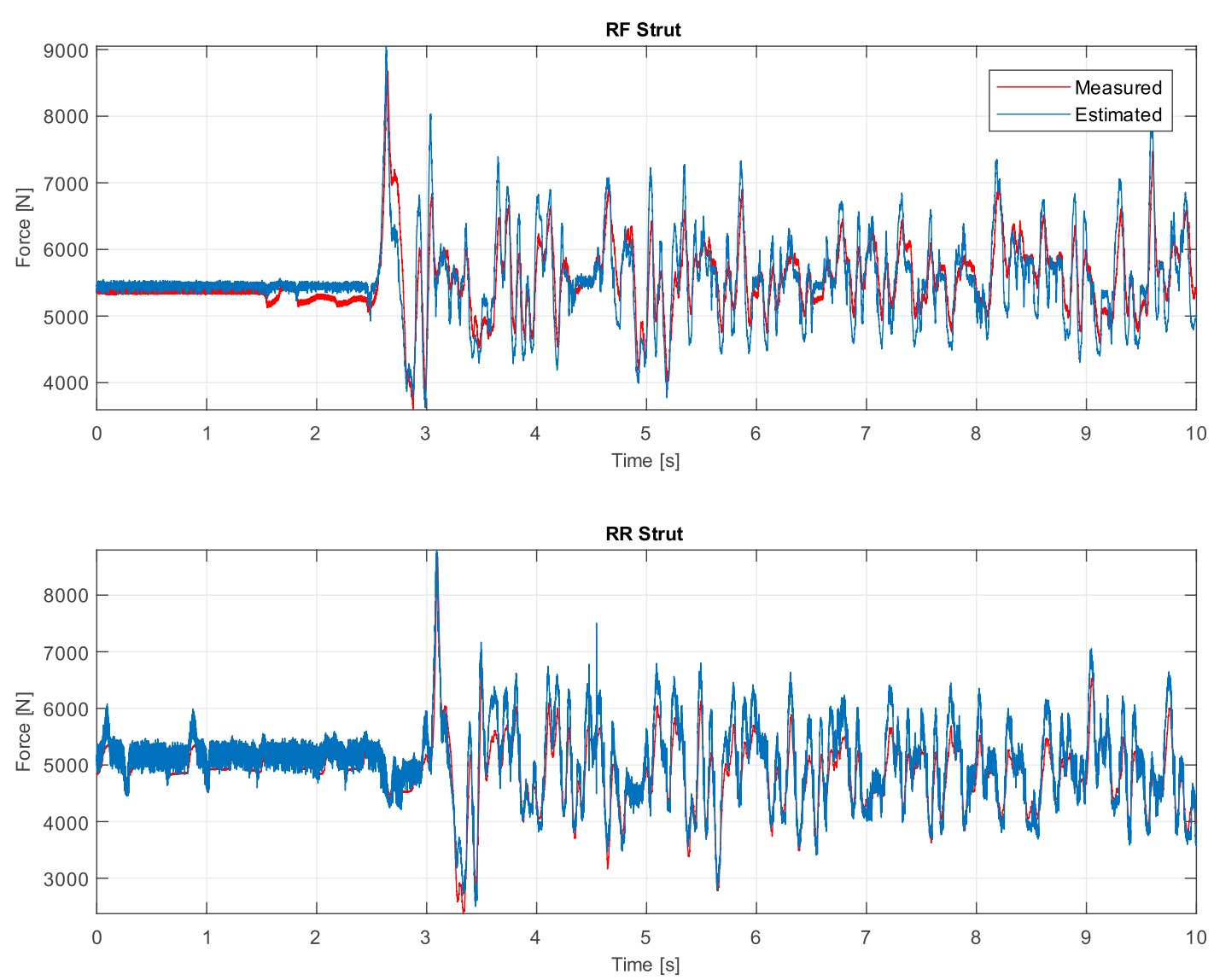

Fig. 7. Estimation of suspension forces of vehicle driving over Belgian paving
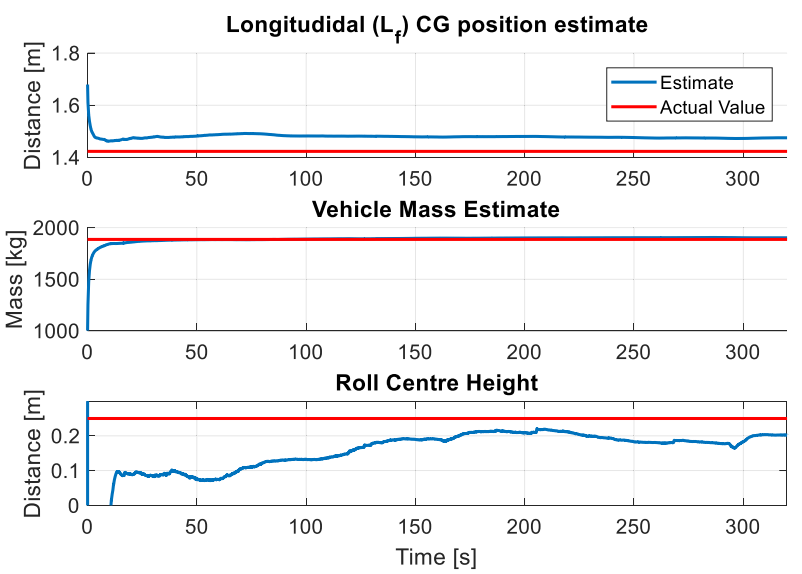

Fig. 8. Estimation of inertial parameters of vehicle during off-road driving

estimated on a SUV vehicle which is driving in a rural environment. During the test the vehicle experienced very little lateral and longitudinal excitation.

\section{Design Case: Parameter Estimation of Tyre- Road Contact Forces}

Two lateral and longitudinal force estimation approaches at the tyre-road contact have been developed: one is based on an Extended Kalman Filter (EKF) and the other one uses an Artificial Neural Network method (ANN) ${ }^{(11)}$. An experiment was carried out using a UTC vehicle instrumented with four wheel transducers which measure the forces and torques for the $\mathrm{x}, \mathrm{y}$ and $\mathrm{z}$ directions, and with an Inertial Measurement Unit (IMU) from which it is possible to obtain the vehicle accelerations and angular rates for yaw, pitch, and roll. The vehicle reaches a maximum speed of approximately $60 \mathrm{~km} / \mathrm{h}$ while achieving a maximum lateral acceleration about $4,5 \mathrm{~m} / \mathrm{s}^{2}$.

The results obtained with both techniques have been validated against experimentally-collected data. To illustrate the capabilities of the estimators developed, some representative results are reproduced here. More details of the study are found in (11). Figure 9 and respectively Fig. 10 present measured (black dashed line) and estimated results (red continuous line for EKF and blue dotted line for ANN) of the lateral, respectively longitudinal forces for the front tyres at the tyreground interface.

Both methods show good agreement with the measurements, each one of the methods performing slightly better for one condition or another. Overall, their errors are relatively low when compared with the test data for the complex maneuvers considered (acceleration, steering, and braking), and thus their use in an ICC is feasible.

\section{Design Case: Ride Comfort Difference Thresholds for EVE Vehicle Demonstrator on 4-poster Test Rig}

The ICC should not only provide objective improvements in safety and comfort but also improvements that results in the subjective perception thereof by the vehicle driver and occupants. The ride comfort of vehicles is a complex field 


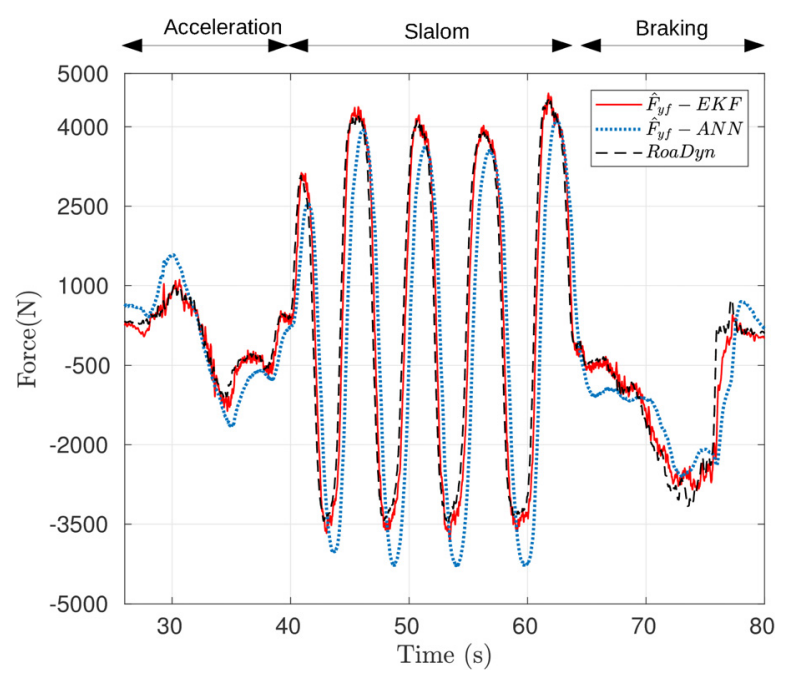

Fig. 9. EKF and ANN parameter estimation results for the lateral force of front tyres compared with experiment (11)

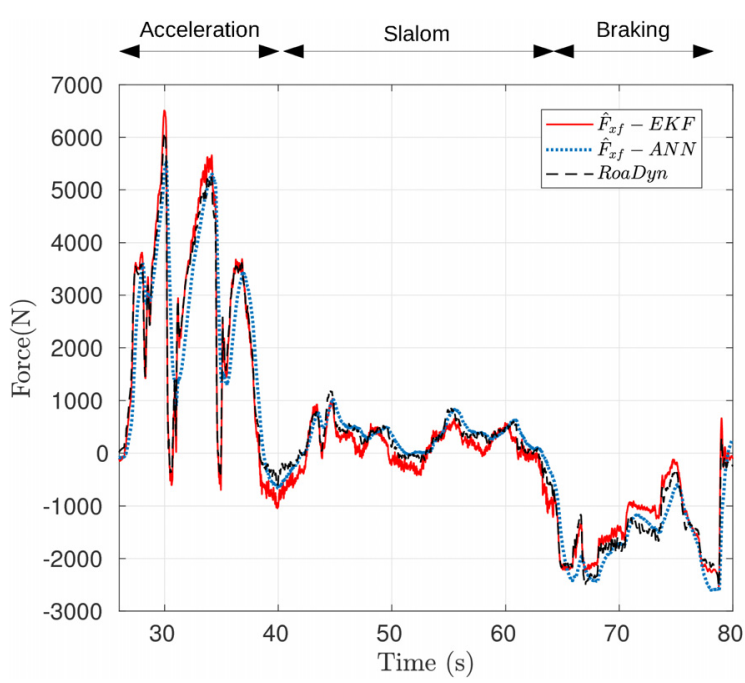

Fig. 10. EKF and ANN parameter estimation results for the longitudinal force of front tyres compared with experiment (11)

that incorporates psychological effects, ergonomics, climate, noise and vibration exposure. Occupants' subjective evaluation or judgement of the vibration experienced while driving might influence their opinion of a vehicle ${ }^{(12)(13)}$. Vibration can be measured during experimental testing or in simulation, in order to evaluate whether design changes will improve comfort. Methods of measure are capable of measuring changes in vibration that humans cannot perceive ${ }^{(12)}$. Morioka and Griffin $^{(14)}$ mention that it is not known when a reduction in vibration will result in a noticeable improvement in comfort. Research on improving vibration comfort over recent years is based on the assumption that a reduction in vibration will result in an improvement in comfort ${ }^{(14)}$. Having knowledge of the smallest change in magnitude of vibration that can be detected, has relevance towards the decision on the implementation of design changes ${ }^{(12)}$. With this information available the risk of the ICC making changes, for example, to the suspension system, without the occupants noticing a difference can be mitigated.
For vehicle vibration on a seat Mansfield and Griffin ${ }^{(12)}$ defines the difference threshold (DT) as: “...the minimum change in the magnitude of the whole-body vibration required for the seat occupant to perceive the change in magnitude." Weber's law states that the ratio between the stimulus magnitude $(I)$ and the change in stimulus magnitude $(\Delta I)$, that will be just noticeable, are at a constant ratio $(C=\Delta I / I)$. $C$ is the relative difference threshold (RDT) and $\Delta I$ is the absolute difference threshold (ADT).

Mansfield and Griffin ${ }^{(11)}$ state that although frequency weightings have been established to predict relative discomfort and compare different vehicles, there has been little research in the DTs of whole-body vibration. Studies have estimated DTs for participants seated on a rigid surface for sinusoidal vertical vibration ${ }^{(14)-(16)}$ and participants seated on a car seat for random vertical vibration (12) and (17). When driving in a vehicle, occupants might be exposed to not only vertical vibration, but also lateral, longitudinal, roll, pitch and yaw vibration. Therefore, DTs were estimated for drivers seated in the EVE vehicle demonstrator on a 4-poster test rig, exposed to all six axes of vibration as if driving in a straight line over a road.

The required ethical clearance was obtained from the Engineering, Built Environment and Information Technology (EBIT) faculty Research Ethics Committee of the University of Pretoria. The participants consisted of 10 male engineers, all of whom work in the field of vehicle engineering. The EVE vehicle demonstrator was placed on the 4-poster test rig of Tenneco Automotive. The actuators could excite up to $40 \mathrm{~Hz}$ at the required displacements. Acceleration was measured between the seat surface and the ischial tuberosity of the driver and at three locations on the seat rail. DTs were estimated for two road profiles. The two road profiles were generated from a road profile that represents a test track used for ride comfort evaluations. Vehicle speed during evaluations over the test track was $80 \mathrm{~km} / \mathrm{h}$. The one road profile, referred to as Road 0p71, was generated by scaling the magnitude of the vertical displacement of the test track down to $71 \%$. A second road profile was generated to resemble a less rough road. The magnitude of the test track was therefore scaled down to $30 \%$ to form the second road profile, Road 0p30. These are the two reference stimuli used in this study as the displacement inputs to the 4-poster rig. Figure 11 shows the two reference stimuli of the front left actuator on the 4-poster rig superimposed on ISO roads ${ }^{(18)}$.

The up down transformed response (UDTR) procedure, used to estimate DTs, requires that the participant be presented with a reference and an alternative stimulus ${ }^{(12)}$. The alternative stimuli, for each reference road, were generated by multiplying the magnitude of the vertical displacement of the specific reference road with a multiplication factor. The multiplication factors were determined through an iterative process. The aim was to get a $3 \%$ change in the weighted root mean square (r.m.s.) of the vertical acceleration as measured on the seat rail's FL position, between alternative stimuli. The UDTR procedure with a three-down-one-up rule was selected as the psychophysical testing procedure to estimate the DTs. The method was selected based on the principal that it estimates a DT for a participant at a $79.4 \%$ probability level and has been used by Mansfield and Griffin ${ }^{(12)}$ as well as 


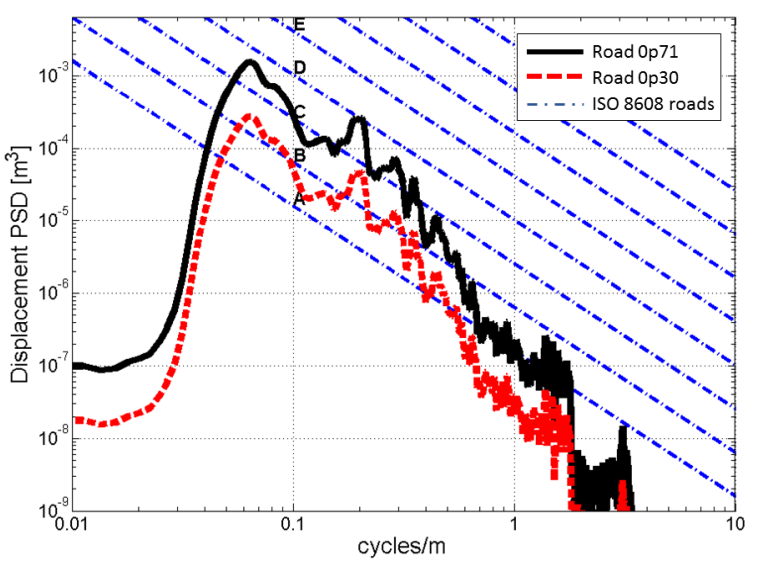

Fig. 11. Reference road profiles used as input to the front left actuator on 4-poster rig

by Morioka and Griffin ${ }^{(14)}$. The order in which the two roads were presented to participants was randomized. DTs were calculated from the vertical acceleration measured by the seat pad from every trial. The acceleration data was weighted in the frequency domain during post processing by using the approximation of the $W_{b}$ weighting function as defined in BS $6841^{(19)}$. All frequency content below $0.5 \mathrm{~Hz}$ and above $80 \mathrm{~Hz}$ was discarded. The r.m.s. was used to represent the magnitude of acceleration as the crest factor was below six as specified in BS $6841^{(19)}$ for all accelerations. The BS $6841^{(19)}$ was used, instead of the more recent ISO 2631-1 ${ }^{(20)}$, in order to compare RDT results with those obtained by Mansfield and Griffin $^{(12)}$ as this is the only other study to have conducted DT testing with vehicle seat exposing participant to real life vibration inputs. The ADT for a set, $\Delta I_{i}$, was calculated from Eq. (1) where $i$ is the number of the set, $P_{i}$ is the average of the alternative stimulus at a peak where there are three consecutive correct responses, $P_{\text {refi }}$ is the average of the three reference magnitudes at a peak, $T_{i}$ is the magnitude of the alternative stimulus at a trough and $T_{\text {refi }}$ is the magnitude of the reference stimulus at a trough. The RDT for a set, $C_{i}$, was calculated from Eq. (2). The variables $P_{\text {refi1 }}, P_{\text {refi2 } 2}$ and $P_{\text {refi3 }}$ are the r.m.s. magnitude of the three reference stimuli that forms a peak, $m$ is the number of sets, $k$ is the number of the first set used in the calculation, and $n$ is the number of consecutive correct responses. The numerator of Eq. (2) calculates the average across all reference stimuli which forms part of the peaks and troughs used in the DT calculation. The ADT across all sets was calculated from Eq. (3) by taking the average of the RDTs for each set. The RDT across all sets was calculated from Eq. (4) by taking the average across all sets.

$$
\begin{aligned}
& \Delta I_{i}=\frac{\left(P_{i}-P_{r e f i}\right)+\left(T_{i}-T_{r e f i}\right)}{2} . \\
& c_{i}=\frac{\Delta I_{i}}{\sum_{i=k}^{m}\left(P_{\text {refi } 1}+P_{\text {refi2 }}+P_{\text {refi3 }}+T_{\text {refi }}\right) /(m-k)(n+1)} \\
& \Delta I=\frac{\sum_{i=k}^{m} \Delta I_{i}}{m-k} . \\
& c=\frac{\sum_{i=k}^{m} c_{i}}{m-k} . \\
& \text {................. (2) }
\end{aligned}
$$

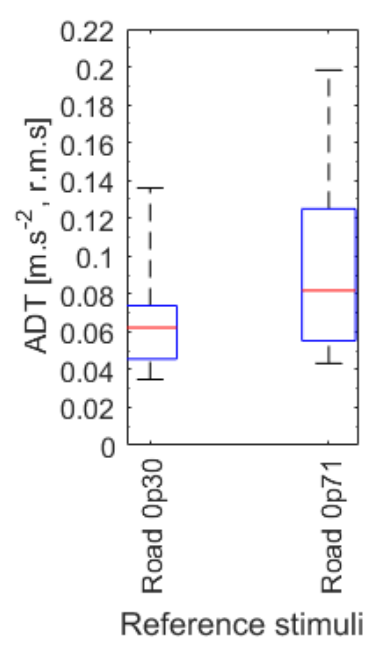

(a)

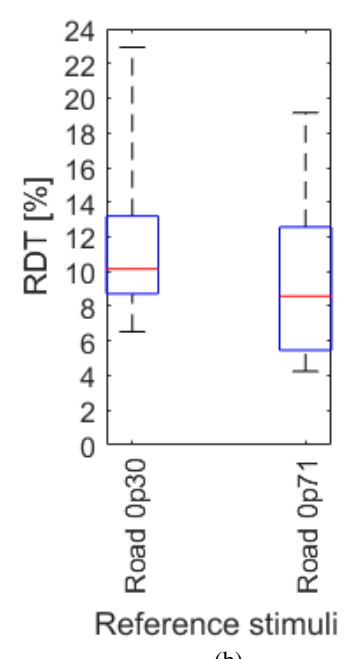

(b)
Fig. 12. Box plots showing the distribution of the ADTs (a) and the distribution of the RDTs (b) for the 10 participants calculated from the weighted vertical seat pad accelerations

The distributions of the ADTs and RDTs for the ten participants for the two reference stimuli (Road 0p30 and Road 0p71) are shown in the box plots in Fig. 12. The median RDT was estimated to be $10.1 \%$ and $8.6 \%$ for the two roads, Road 0p30 and Road 0p71, respectively. Statistically comparing the medians of the RDT between the two stimuli, no significant difference between the medians of RDT of Road 0p30 and Road 0 p71 was found ( $p=.203$, non-parametric related samples Wilcoxon signed rank test). This implies that Weber's law holds for the RDTs estimated from vertical acceleration when a driver is exposed to six axes of vibration while seated in a vehicle on a 4-poster rig. These estimated RDTs can be used by the ICC to ensure that changes are made such that they are noticeable by the vehicle occupants. For example, if a change is made to the suspension system that corresponds to the median RDT, $50 \%$ of the population should be able to correctly identify the more comfortable setting $79.4 \%$ of the time.

When using the $75^{\text {th }}$ percentile RDT it would imply that $75 \%$ of the population should be able to correctly identify the more comfortable setting $79.4 \%$ of the time. It should be noted that the cohort used consisted of male engineers with a technical background in vehicle engineering, therefore, the DT results obtained may therefore not be representative of the broader population. Future work could include investigating the applicability of frequency weighting functions in predicting DTs, DTs for the various axes of vibration, DTs for certain frequency bands as well as the effect of using different psychophysical methods to estimate DTs. Furthermore, it would be important to see what effect real-life driving will have on the DTs and whether DTs estimated in lab conditions (e.g. 4-poster test rigs) are appropriate. This information should enhance the improvements provided by the ICC in terms of comfort.

\section{Design Case: Benchmarking of Wheel Slip Control Methods}

The brake-based wheel slip control (WSC) is the most 


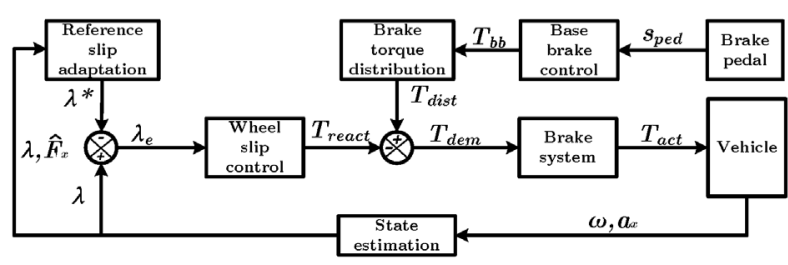

Fig. 13. WSC structure (21)

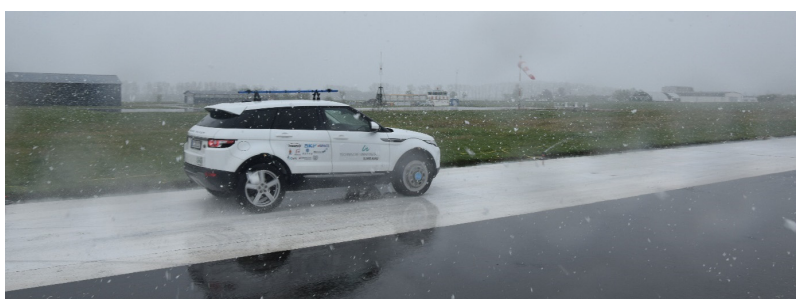

Fig. 14. Tests of the EVE vehicle demonstrator on Alkersleben proving ground in severe weather conditions

important part of the ICC architecture; therefore, its design has considered several competitive strategies at the beginning of the EVE project. The WSC on the vehicle demonstrator is realized with the electro-hydraulic brake actuators that allows to implement a continuous control approach. In this regard, a general structure of the WSC has been proposed as indicated in Fig. 13. The control on the wheel slip is realized through the generation and subtraction of the reactive torque $T_{\text {react }}$ from the individual wheel torques $T_{\text {dist }}$, which are computed from the overall base-brake torque demand $T_{b b}$. The base-brake torque demand is obtained from the brake pedal travel $s_{p e d}$, which is set by the driver. The reference slip $\lambda^{*}$ is calculated from the estimated longitudinal tyre forces $F_{x}$ and actual wheel slip $\lambda$. The actual wheel slip $\lambda$ is computed from the signals of the wheel speed sensors and estimated vehicle velocity. In accordance with the available instrumentation of the EVE vehicle demonstrator, the information about vehicle velocity is taken directly from the VBOX measurement system. Following one of the main targets of the developed ICC, the WSC should guarantee the required driving safety and support the driving comfort. The driving comfort at braking depends mainly on the vehicle jerk, or the first derivative off the longitudinal vehicle acceleration/ deceleration. To dampen the vehicle jerk, the use of continuous control WSC methods allowing smooth tracking of the reference slip without essential oscillations of the wheel velocities can be proposed. In this regard, within the framework of the EVE project, three continuous WSC strategies are elaborated: Proportional-integral (PI) control with anti-windup for integral part of the controller; Conventional sliding mode control (SMC); Integral sliding mode control (ISMC) with chattering avoidance.

During the EVE experimental programme, a special series of tests has been done to compare the WSC algorithms and to make the decision for the final design of the wheel slip controller. For this purpose, the EVE vehicle was tested for the straight-line braking on the Alkersleben proving ground (Germany) in severe weather conditions, as presented in Fig. 14. In all the tests, the ICC mode has been activated to consider the influence of the actuators of suspension and tyre pressure control system.

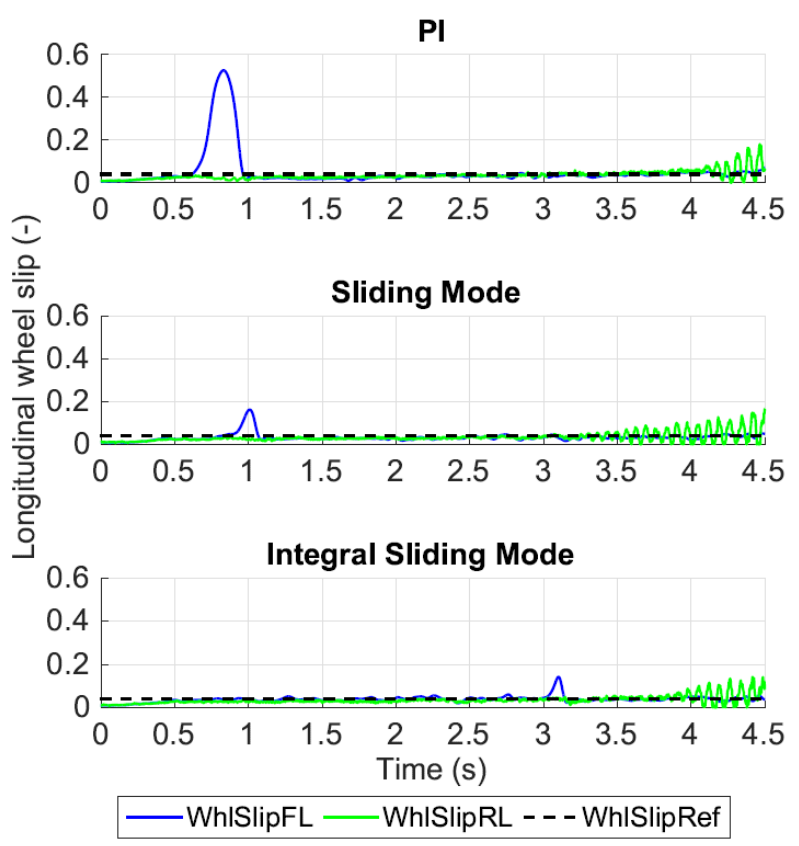

Fig. 15. Wheel slip during the straight-line braking on the low- $\mu$ road (21)

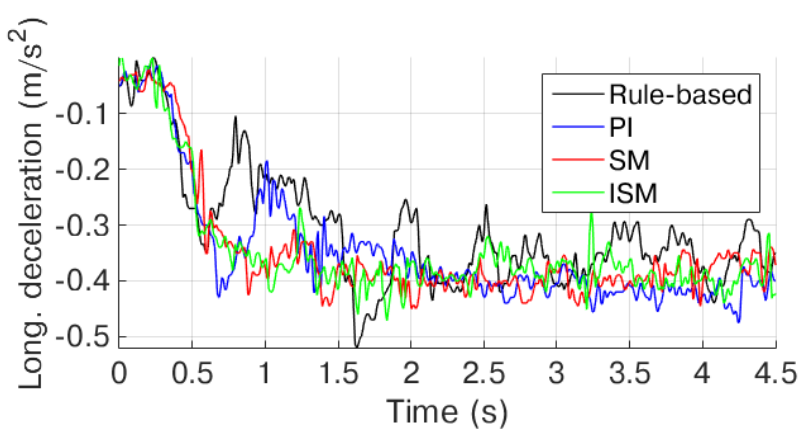

Fig. 16. Vehicle deceleration during the straight-line braking on the low $-\mu$ road (21)

Figure 15 shows an example of the test results for reference trials on low-friction surface $(\mu=0,2 \ldots 0,3)$ and the initial braking velocity of $60 \mathrm{~km} / \mathrm{h}$. It was clearly observed that ISMC approach ensured minimal slip oscillations, and such wheel dynamics correspondingly caused a low vehicle jerk that can be evaluated from Fig. 16.

Hence, the experimental results allowed to conclude that a better candidate for the WSC implementation is the integral sliding mode approach. This approach demonstrated a higher robustness to disturbances and suppression of chattering phenomena. The ISM algorithm was therefore selected for the use in the ICC architecture. As a result, it assures a seamless integration with other chassis subsystems to achieve simultaneously enhanced performance in terms of driving safety and comfort.

\section{Design Case: Distributed Testing Procedures}

Industrial development of such complex automotive systems as ICC requires several billion kilometers of virtual and road tests to reach sufficient functionality in terms of robustness and fail-safe operation. Therefore, there is a strong demand on new time-efficient procedures allowing rapid prototyping, design, and validation of automotive systems. Their 
development implements usually software-in-the-loop (SIL), model-in-the-loop, hardware-in-the-loop and test-rig-in-theloop (TRIL) tools, which together can be referred as components of X-in-the-loop (XIL) environment. A variant of generic XIL architecture is shown on Fig. 17. It has an open interface and can be extended with additional virtual software environments and test rigs depending on the specific research

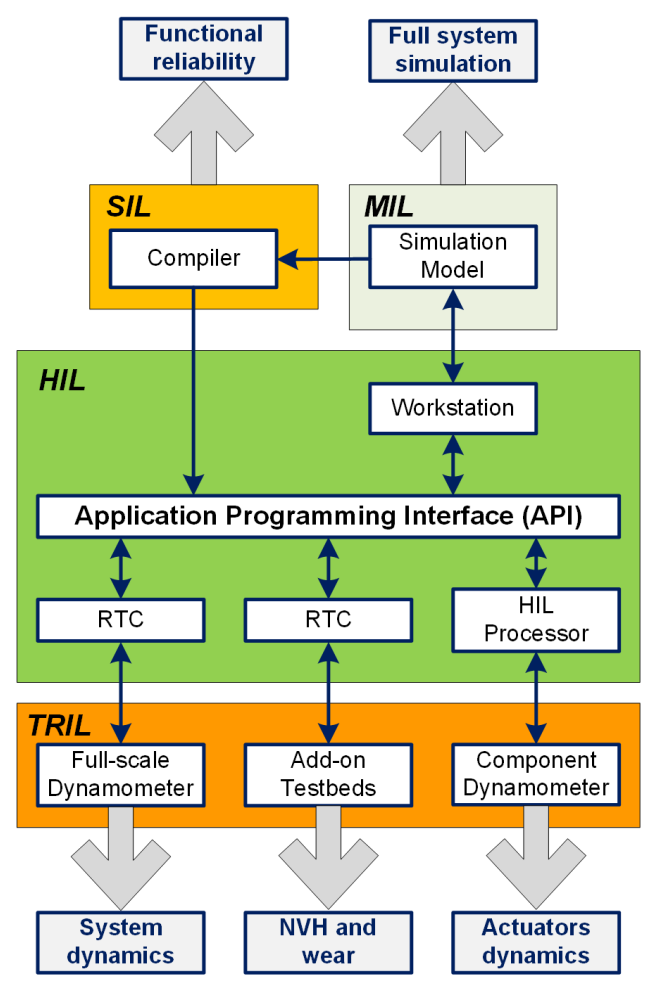

Fig. 17. Generic variant of XIL architecture for vehiclerelates studies (22) and development tasks. However, it is difficult to collect all components of such sophisticated architecture within one physical host.

Thus, the EVE project considered sharing and distributing the development tasks and the corresponding design and testing components between different hosts or partners. This step has led to the establishment of collaborative experimental environments subjected to real-time holistic networking that allows designing experiments, which are not possible in the case of stand-alone use of test rigs or simulators. Such an environment can handle complex test scenarios with simultaneous investigations of the control performance of vehicle systems, wearing processes in chassis components, and the driving comfort.

The proposed architecture can be realized with many specific variants of test rig coupling. One of the first variants has included the coupling of the HIL brake component test rig, the brake dynamometer and the real vehicle simulator (i) to define experimentally the influence of the hydraulic system dynamics on the braking control performance and (ii) to assess tribological processes as particle emission and $\mathrm{NVH}$ in the brakes under various braking maneuvers, Fig. 18. An embedded real-time simulation is used by the connection of the test rigs. It is realized with AVL InMotion platform and vehicle software simulators as dSPACE ASM or IPG CarMaker. This variant has been applied for WSC designing. The WSC requires consideration of the hysteresis in the brake friction pair (brake disc/pad) to improve the control robustness. For this purpose, XIL architecture is implemented as follows: the brake dynamometer delivers information about the wheel torque to the simulation software at AVL InMotion platform; the electro-hydraulic brake system at the testing platform uses the signals about brake pressure demand and wheel speeds realizing wheel slip control functions. Compared to the simulation, the proposed procedure considers in

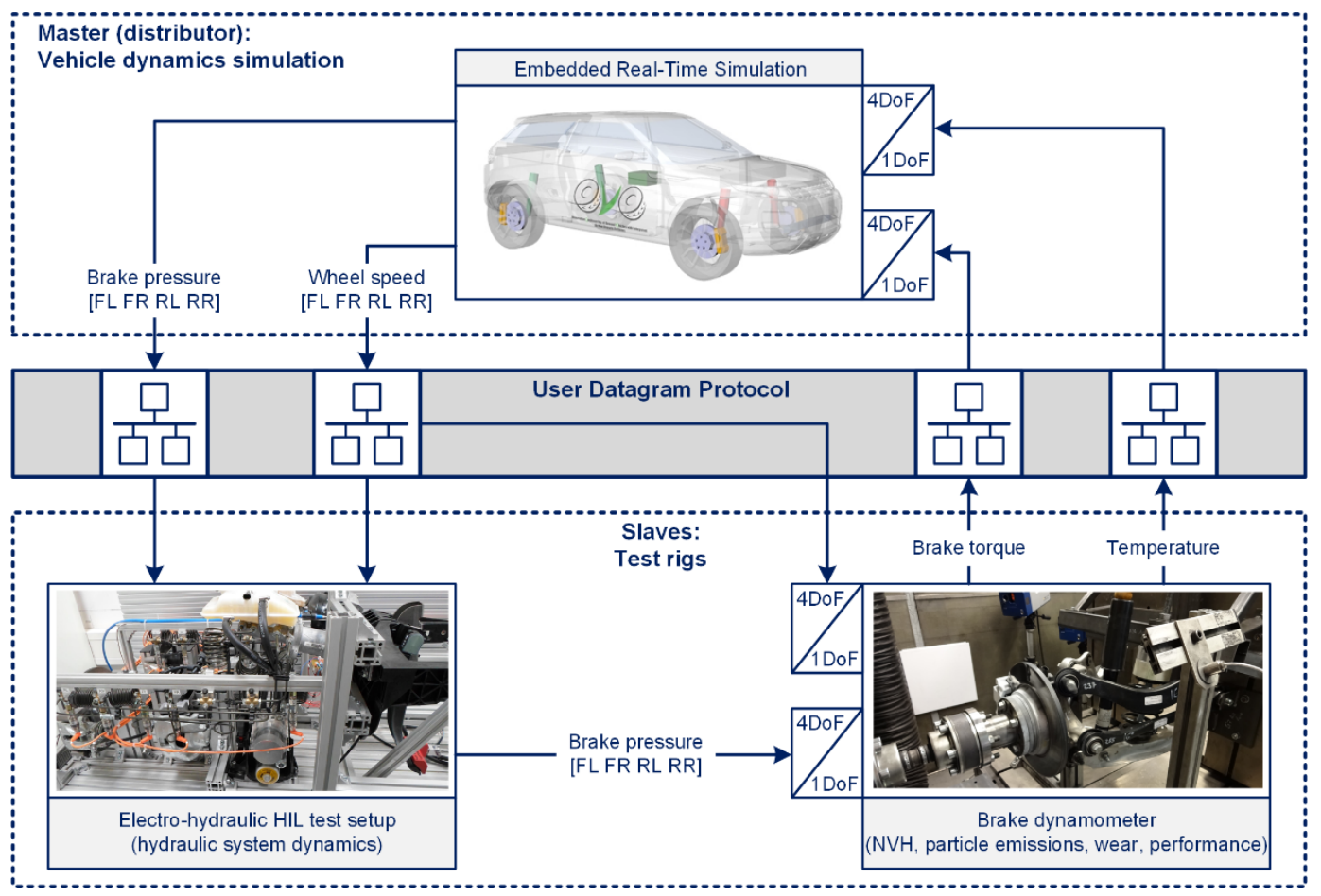

Fig. 18. XIL-coupling of test rigs (4) 
real-time various tribological phenomena in brakes, as hysteresis.

It allows avoiding the implementation of complex tribological models in the WSC with the accounting for the temperature of the friction area, relative velocity between friction components, pressure distribution in the contact area and pressure gradient.

The presented methodology reaches a higher level of complexity in the case of geographical distribution. To address this case, a feasibility check for sufficient real-time connectivity has been done for remote and shared experiments, where various parts of tests are performed at different geographical hosts in Germany, the Netherlands, South Africa and USA. This feasibility check confirmed reliable performance of the distributed testing procedures even in these intercontinental conditions. More detailed information about these tests is presented in (22).

\section{Summary}

Previous sections illustrated only few examples of specific design procedures implemented by the development of the integrated chassis control within the EVE project. Additional, extended information about the project outcomes is presented in the consortium publications, among which several are mentioned here, as follows: dedicated to tyre modelling and testing ${ }^{(23)-(27)}$, ICC hardware components ${ }^{(28)-(30)}$, control methods for ICC and its subsystems ${ }^{(31)-(34)}$, and vehicle and system testing procedures ${ }^{(35)(36)}$. It should be noted that the project not only realized complex engineering task of efficient ICC design but brought a strong professional impact for research staff participated in the development activities. The EVE clearly demonstrated how the intersectoral and international collaboration between unique research environments allows exploring cutting-edge knowledge and technologies in ground vehicle and control systems engineering.

\section{Acknowledgment}

This work was supported by the European Union Horizon 2020 Framework Program, Marie Skdowska-Curie actions, under grant agreement no.645736.

\section{References}

( 1 ) V. Ivanov and D. Savitski: "Systematization of integrated motion control of ground vehicles", IEEE Access, Vol.3, pp.2080-2099 (2015)

( 2 ) Y. Ohyama: "A totally integrated vehicle electronic control system", SAE Technical Paper Series, paper no.881772 (1988)

( 3 ) Y. Yokoya, et al.: "Integrated control system between active control suspension and four wheel steering for the 1989 CELICA", SAE Technical Paper Series, paper no.901748 (1990)

( 4 ) V. Ivanov, et al.: "Collaborative engineering of integrated chassis control for ground Vehicle", Proc. of IEEE International Conference on Mechatronics (ICM), Gippsland, Australia (2017)

( 5 ) D. Savitski, et al.: "Improvement of traction performance and off-road mobility for a vehicle with four individual electric motors: Driving over icy road", Journal of Terramechanics, Vol.69, pp.33-43 (2017)

( 6 ) A. Bhoopalam, C. Sandu, and S. Taheri: "Experimental investigation of pneumatic tire performance on ice: Part 1-Indoor study", Journal of Terramechanics, Vol.60, pp.43-54 (2014)

( 7 ) J.M. Baldwin, D.R. Bauer, and K.R. Ellwood: "Accelerated Aging of Tires, Part II", Rubber Chemistry and Technology, Vol.78, No.2 (2005)

( 8 ) A.K. Madhusudhanan, M. Corno, M.A. Arat, and E. Holweg: "Load sensing bearing based road-tyre friction estimation considering combined tyre slip", Mechatronics, 39, pp.136-146 (2016)

(9) R.E. Kalman: "A New Approach to Linear Filtering and Prediction
Problems", Transactions of the ASME. Journal of Basic Engineering 82, pp.35-45 (1960)

(10) S.J. Julier and J.K. Uhlman: "A New Extension of the Kalman Filter to Nonlinear Systems", In Proc. Of AeroSense: The 11th Int. Symp. on Aerospace/ Defence Sensing, Simulation and Controls (1997)

(11) S. McBride, C. Sandu, A. Alatorre, and A. Victorino: "Estimation of vehicle tire-road contact forces: A comparison between artificial neural network and observer theory approaches", SAE Paper no.2018-01-0562, WCX ${ }^{\mathrm{TM}}$ : SAE World Congress Experience, April 10-12, 2018, Detroit, MI, U.S.A. (2018)

(12) N. Mansfield and M. Griffin: "Difference thresholds for automobile seat vibration", Appl. Ergonomics, Vol.31, No.3, pp.255-261 (2000)

(13) T. Gillespie: "Fundamentals of Vehicle Dynamics", Society of Automotive Engineers, Warrendale (1992)

(14) M. Morioka and M. Griffin: "Difference thresholds for intensity perception of whole-body vertical vibration: Effect of frequency and magnitude", J. Acoustical Society Am., Vol.107, No.1, pp.620-624 (2000)

(15) Y. Matsumoto, S. Maeda, and Y. Oji: "Influence of frequency on difference thresholds for magnitude of vertical sinusoidal whole-body vibration", Industrial Health, Vol.40, No.4, pp.313-319 (2002)

(16) N. Forta, M. Morioka, and M. Griffin: "Difference thresholds for the perception of whole-body vertical vibration: dependence on the frequency and magnitude of vibration", Ergonomics, Vol.52, No.10, pp.1305-1310 (2009)

(17) W. Pielemeier, V. Jeyabalan, R. Meier, and N. Otto: "Just noticeable differences in vertical vibration for subjects on an automobile seat", Proceedings of the 32nd United Kingdom Group Meeting on Human Response to Vibration, Southampton (1997)

(18) International Organization for Standarization, ISO 8608: "Mechanical vibration-Road surface profiles-Reporting of measured data" (1995)

(19) British Standards Institution, BS 6841: "British Standard Guide to measurement and evaluation of human exposure to whole-body mechanical vibration and repeated shock" (1987)

(20) International Organization for Standarization, ISO 2631-1: "Mechanical vibration and shock - evaluation of human exposure to whole-body vibration" (1997)

(21) D. Savitski, et al.: "Individual wheel slip control using decoupled electrohydraulic brake system", Proc. of IEEE IECON Confrence, Beijing, China (2017)

(22) V. Schreiber, et al.: "Shared and Distributed X-in-the-Loop Tests for Automotive Systems: Feasibility Study", IEEE Access, Vol.99 (2018)

(23) A. Albinsson, et al.: "Tire vibration considerations in vehicle based tire testing", Proc. of the 36th Annual Meeting of The Tire Society, Akron, Ohio, USA (2017)

(24) A. Khan and C. Sandu: "Design and Manufacturing of a Clutch and Brake System for Indoor Tire Testing", Proc. of ASME IDETC/CIE, 19th International Conference on Advanced Vehicle Technologies, Cleveland, OH, USA (2017)

(25) R. He, et al.: "Investigating the Parameterization of Dugoff Tire Model Using Experimental Tire-Ice Data", SAE Int. J. Passeng. Cars - Mech. Syst., Vol.10, No.1 (2017)

(26) T. Botha, et al.: "Kinematic analysis of a tyre rolling over rough terrain using digital image correlation", Proc. of 13th European Conference of the International Society of Terrain-Vehicle System, Rome, Italy (2015)

(27) P.S. Els, et al.: "Comparison of Tire Footprint Measurement Techniques", Proc. of ASME International Design Engineering Technical Conferences and Computers and Information in Engineering Conference, Charlotte, USA (2016)

(28) S. Kerst, B. Shyrokau, and E. Holweg: "Reconstruction of wheel forces using an intelligent bearing", Proc. of SAE World Automotive Congress, Detroit, USA (2016)

(29) D. Savitski, et al.: "Advanced Control Functions of Decoupled Electro- Hydraulic Brake System", Proc. of IEEE 14th International Workshop on Advanced Motion Control, Auckland, New Zealand (2016)

(30) S. Kerst, B. Shyrokau, and E. Holweg: "A semi-analytical bearing model considering outer race flexibility for model based bearing load monitoring", Mechanical Systems and Signal Processing, Vol.104, pp.384-397 (2018)

(31) D. Savitski, et al.: "Sliding mode approach in semi-active suspension control", in Book: Sliding Mode Control of Vehicle Dynamics, Chapter: 6, Publisher: Institution of Engineering and Technology, Editors: Antonella Ferrara (2017)

(32) D. Roethof, et al.: "Influence of Active Camber Control on Steering Feel", SAE Int. J. Passeng. Cars - Mech. Syst., Vol.9, No.1, pp.124-134 (2016)

(33) A. Aksjonov, K. Augsburg, and V. Vodovozov: "Design and simulation of the robust ABS and ESP fuzzy logic controller on the complex braking maneuvers", Applied Sciences, Vol.6, No.12 (2017)

(34) D. Savitski, et al.: "Influence of the Tire Inflation Pressure Variation on Braking Efficiency and Driving Comfort of Full Electric Vehicle with Continuous 
Anti-Lock Braking System", SAE Int. J. Passeng. Cars- Mech. Syst., Vol.8, No.2 (2015)

(35) V. Žuraulis, et al.: "Modelling and validation of a testing trailer for ABS and tyre interaction on rough terrain", Proc. of the 9th International Conference \& 14th European-African Regional Conference of the ISTVS, Budapest, Hungary (2017)

(36) V. Schreiber, et al.: "Advanced braking system control prototyping using networked hardware-in-the-loop technique", Proc. of Eurobrake Conference, Milan, Italy (2016)

Valentin Ivanov

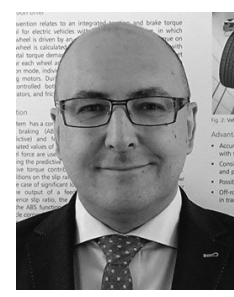

(Non-member) received the Ph.D. degree in 1997 and the D.Sc. degree in 2006 from Belarusian National Technical University, Minsk. In 2017 he has received Dr.-Ing. habil. from Technische Universität Ilmenau, Germany. In July 2007, he became an Alexander von Humboldt Fellow, and, in July 2008, he became a Marie Curie Fellow with TU Ilmenau, Germany. He is currently EU Project Coordinator with the Automotive Engineering Group, TU Ilmenau. His research fields are vehicle dynamics, electric vehicles, automotive control systems, chassis design, and fuzzy logic. Valentin Ivanov is a member of IEEE, SAE International, Society of Automotive Engineers of Japan, and the International Society for Terrain-Vehicle Systems.

Dzmitry Savitski (Non-member) received the Dipl.-Ing. degree in

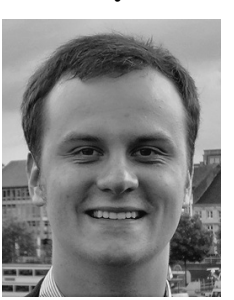
Automotive Engineering from Belarusian National Technical University, Minsk, in 2011. From 2011 to 2018, he worked toward Dr.-Ing. degree in Automotive Engineering at Technische Universität Ilmenau, Germany. Mr. Savitski is a member of the Association of German Engineers and SAE International.

Klaus Augsburg (Non-member) received Dr.-Ing. degree in 1985

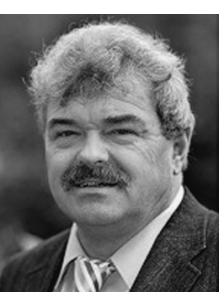
from Technische Universität Dresden, Germany. From 1984 to 1993 he worked in industry on leading engineer positions and then in 1993-1999 as Senior Assistant at TU Dresden. In 1999 he became position of Full Professor and Chair of Automotive Engineering Group at Technische Universität Ilmenau, Germany. In 2011 Prof. Augsburg founded Thuringian Centre of Innovation in Mobility, where he is coordinating many industrial and public research projects. Prof. Augsburg is author of more than 100 research papers, guest lectures and patents. He is a member of the Association of German Engineers, Chairman Workgroup Automotive Engineering VDI Thüringen, and CEO SteinbeisTransferzentrum Fahrzeugtechnik.

Schalk Els (Non-member) received the Ph.D. degree in 2006 from the

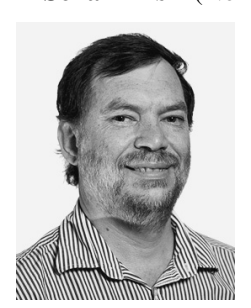
University of Pretoria in South Africa. He worked in industry from 1994-1999 where he was involved with developing and testing wheeled military vehicles. This included semi-active dampers and the world's first semi-active hydraulic rotary damper for heavy vehicles. In 1999 he joined the University of Pretoria as a permanent staff member. He is research leader of the Vehicle Dynamics Group. His research is focussed on the use of semi-active spring-dampers to improve ride, handling, rollover propensity and life of off-road and heavy vehicles. This includes tyre, terrain and suspension characterisation and modelling as well as vehicle dynamics control. Schalk is a member of ISTVS, SAE International, ASME and SAIMechE as well as editor for Journal of Terramechanics.

Cor-Jacques Kat (Non-member) holds degrees in Mechanical En-

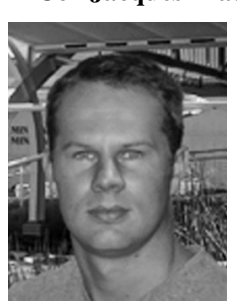
gineering from the University of Pretoria (B.Eng., B.Eng. (Hons), M.Eng., Ph.D.). His Masters and $\mathrm{Ph} . \mathrm{D}$. research was focused on vehicle system and component modelling and testing. His professional experience includes work as a research and development engineer in the automotive industry and he is currently employed by the University of Pretoria as a senior lecturer. His current research includes vehicle dynamics, human factors and biomechanics.

Theunis Botha (Non-member) received a Ph.D. at the University of

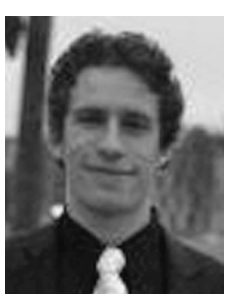
Pretoria in 2015. His Ph.D. research focus was the application of digital image correlation in vehicle dynamics. He is currently employed by the University of Pretoria as a senior lecturer. His research focus is digital image correlation, vehicle dynamics control and estimation. He is a member of the International Society of Terrain Vehicle Systems.

Miguel Dhaens

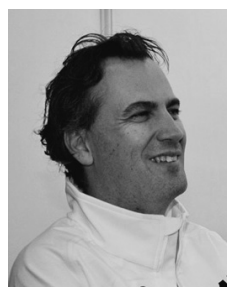

(Non-member) is coordinator of advances research activities for Tenneco. He graduated as electro mechanical engineer in 1994 and since has worked for 15 years in Formula 1 for Ilmor Engineering (UK) and Toyota Motorsport (D). After his F1 career he was R\&D program manager at a Belgian re-search institute for last 4 years and joined Tenneco last year is heading all research activities, involving being responsible for the research road map and the advanced chassis research group, which is looking at new technologies and techniques for use into future Tenneco products.

Corina Sandu (Non-member) is a Professor in the Mechanical Engi-

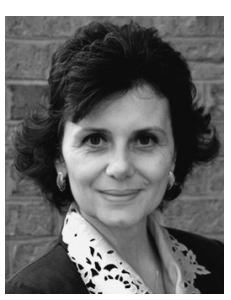
neering Department at Virginia Tech, Associate Department Head for Graduate Studies, and Director of the Terramechanics, Multibody, and Vehicle Systems (TMVS) Laboratory. Before joining Virginia Tech in 2003, Dr. Sandu worked at Michigan Tech for three years. She graduated with an Engineer Diploma from the University "Politehnica" of Bucharest, Romania (1991), and M.S. (1995) and Ph.D. (2000) degrees in Mechanical Engineering from the University of Iowa, U.S.A. Dr. Sandu's research expertise lies in vehicle dynamics (suspension, handling, ride, performance), terramechanics (vehicle-terrain interaction, tire/track modeling, vehicle mobility, soil/terrain modeling) and multibody dynamics (modeling, simulation, uncertainty quantification, parameter estimation, sensitivity analysis, design optimization). She published over 160 peer-reviewed journal and conference proceedings papers, and has over 290 other papers, reports, book chapters, posters, and presentations. Dr. Sandu is the Chair of the ASME Design Engineering Division and and the VicePresident of the International Society for Terrain-Vehicle Systems. She is the Editor-in-Chief of SAE International Journal of Commercial Vehicles and of the Journal of Mechanics Based Design of Structures and Machines, and Associate Editor of the ASME Journal of Computational and Nonlinear Dynamics. Dr. Sandu is past recipient of SAE Ralph R. Teetor Educational Award (2007), SAE Forest R. McFarland Award (2013), and Rodica Baranescu Award for Technical and Leadership Excellence in Commercial Vehicles Engineering (2013). She received the Dean's Award for Excellence in Service (2012) and Virginia Tech Teacher of the Week (2017). Dr. Corina Sandu is an ASME Fellow, and SAE Fellow, and a Marie Skłodowska-Curie Fellow. 
Rui He (Non-member) is a Ph.D. candidate in the Mechanical Engi-

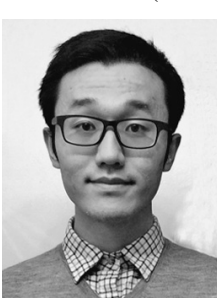
neering Department at Virginia Tech. He graduated with B.Eng. (2014) in Mechanical Design, Manufacturing and Automation from Huazhong University of Science and Technology, China, and B.Eng. with Honours Class I (2014) in Mechanical Engineering from the University of Birmingham, UK. From 2013 to 2014 , he was an undergraduate research assistant in Vehicle Dynamics Group at the University of Birmingham led by Dr. Oluremi Olatunbosun. Since 2014,

he has been a graduate research assistant in the Terramechanics, Multibody, and Vehicle Systems (TMVS) Laboratory at Virginia Tech led by Prof. Corina Sandu. His research interest lies in tire and vehicle dynamics (both on-road dynamics and off-road dynamics), terramechanics, and dynamical system and control in automotive engineering. Rui is a member of the International Society for Terrain-Vehicle Systems.

Sterling McBride (Non-member) received his B.S. in Mechanical En-

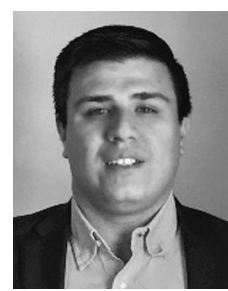
gineering from Universidad San Francisco de Quito, Ecuador in 2015. During the same year he started his Master's Degree in Mechanical Engineering at Virginia Tech and graduated in 2017. His main research interests include the development of innovative wind turbine noise and vibrations prediction tools, tire vibro-acoustic response models, and vehicle dynamic parameters estimation and control. Mr. McBride is a member of ASME, SAE and the Acoustical Society of America. Currently, he is pursuing his Ph.D. at Virginia Tech, focusing on novel tire-pavement interaction noise modeling tools.
Angel Gabriel Alatorre Vazquez (Non-member) is an Electronic En-

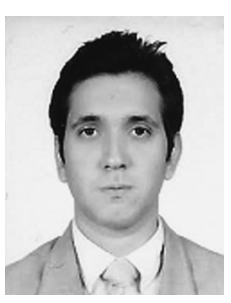
gineer graduated from Instituto Technologic de Culiacan in Mexico on November 2009. He worked from January 2010 to June 2012 on the Federal Electrical Company where he led a team consisting of 15 members. He holds a Master of Sciences (MSc) in Automatic Control from CINVESTAV (Centro de Investigacion y Estudios Avanzados del Instituto Politecnico Nacional), Mexico. He joined General Electric Aviation Business, Mexico on 2015, where he was in charge of design modifications to the engine control logic software while maintaining the Federal Aviation Administration certification according to client needs and requirements. Currently, he is pursuing a Ph.D. study at the Univesité de Technologie de Compiègne, France through an ITEAM project.

Alessandro Corrêa Victorino (Non-member) received the B.S. de-

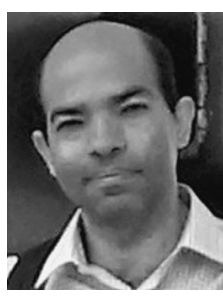
gree in Mechanical Engineering from Federal University of Espírito Santo (UFES) in 1996, the M.S. in Mechanical Engineering from State University of Campinas (UNICAMP) in 1998, and a Ph.D. in Robotics Automation and Control from National Institute for Research in Computer Science and Control (INRIA) in 2002. He defended a "Habilitation à Diriger des Recherches" (HDR) at University of Technology of Compiène (UTC), Compiègne,

France, in 2012. Since 2006, he is an Associate Professor in the Computer Engineering Department at the UTC and member of the Heudiasyc laboratory UMR CNRS 7253. His research interests are in the field of robotic and mechatronic systems, more precisely in the area of intelligent and robotic vehicles, the development of autonomous navigation and driver assistance systems, integrating vehicle dynamics estimation, advanced control techniques, robotic perception and multi-sensor data fusion. 